\title{
Fat injection to correct contour deformities of the reconstructed breast: a single surgeon experience
}

\author{
Youssef Tahiri' ${ }^{1}$, Jonathan Kanevsky², Joshua Vorstenbosch ${ }^{3}$, James Lee ${ }^{2}$, Karl Schwarz ${ }^{4}$ \\ ${ }^{1}$ Department of Surgery, Division of Plastic and Reconstructive Surgery, Riley Hospital for Children, Indiana University, Indianapolis, \\ IN 46202, USA. \\ ${ }^{2}$ Department of Surgery, Division of Plastic and Reconstructive Surgery, McGill University Health Centre, Montreal, QC H3G 1B3, \\ Canada. \\ ${ }^{3}$ Department of Surgery, Section of Plastic Surgery, University of Manitoba, Winnipeg, MB R3T 2N2, Canada. \\ ${ }^{4}$ Schwarz Plastic Surgery, Montreal, QC H3G 1B9, Canada.
}

Address for correspondence: Dr. Karl Schwarz, Schwarz Plastic Surgery, Montreal, QC H3G 1B9, Canada. E-mail: kaschwarz@gmail.com

\begin{abstract}
Aim: Autologous fat grafting has gained acceptance as a technique to improve aesthetic outcomes in breast reconstruction. The purpose of this study was to share our clinical experience using autologous fat injection to correct contour deformities during breast reconstruction. Methods: A single surgeon, prospectively maintained database of patients who underwent autologous fat injection during breast reconstruction from January 2008 to November 2013 at McGill University Health Center was reviewed. Patient characteristics, breast history, type of breast reconstruction, volume of fat injected, and complications were analyzed. Results: One hundred and twenty-four patients benefited from autologous fat injection from January 2008 to November 2013, for a total of 187 treated breasts. The patients were on average 49.3 years old ( \pm 8.9 years). Fat was harvested from the medial thighs $(20.5 \%)$, flanks $(39.1 \%)$, medial thighs and flanks $(2.9 \%)$, trochanters $(13.3 \%)$, medial knees $(2.7 \%)$, and abdomen $(21.9 \%)$. An average of $49.25 \mathrm{~mL}$ of fat was injected into each reconstructed breast. A total of 187 breasts in 124 patients were lipo-infiltrated during the second stage of breast reconstruction. Thirteen breasts (in 12 separate patients) were injected several years after having undergone lumpectomy and radiotherapy. Of the 187 treated breasts, 118 were reconstructed with expanders to implants, 45 with deep inferior epigastric perforator flaps, 9 with latissimus dorsi flaps with implants, 4 with transverse rectus abdominis myocutaneous flaps, and 13 had previously undergone lumpectomy and radiotherapy. Six complications were noted in the entire series, for a rate of 3.2\%. All were in previously radiated breasts. Average follow-up time was 12 months (range: 2-36 months). Conclusion: Fat injection continues to grow in popularity as an adjunct to breast reconstruction. Our experience demonstrates a low complication rate as compared to most surgical interventions of the breast and further supports its safety in breast reconstruction. However, caution should be used when treating previously radiated breasts.
\end{abstract}

Key words:

Breast, contour deformities, fat injection

\begin{tabular}{|l|l|}
\hline \multicolumn{2}{|c|}{ Access this article online } \\
\hline Quick Response Code: & Website: \\
\hline ⿴囗十 & www.parjournal.net \\
\cline { 2 - 2 } & \\
\hline & \\
\hline
\end{tabular}

\section{INTRODUCTION}

Fat injection is a useful surgical modality to correct anatomic contour deformities. ${ }^{[-3]}$ In 1987, the American Society of Plastic Surgeons published a report discouraging the use of autologous fat injections in the breast due to potential complications related to calcifications and detection of breast cancer. ${ }^{[4]}$ Improvements and technique 
have since enhanced the clinical utility of fat grafting, and autologous fat injection is now commonly used to correct breast defects. ${ }^{[5,6]}$

To date, retrospective studies have shown that complications associated with fat injection markedly decreased with the evolution of fat grafting protocols. ${ }^{[7,8]}$ Calcification and fat necrosis have been shown to correlate with the volume, as well as the technique of fat injection..$^{[9-11]}$ There is also evidence that the volume injected correlates with survival of the grafted fat. ${ }^{[12]}$ The minimally invasive nature of the procedure allows patients to benefit from autologous tissue rather than foreign materials. As such, fat grafting has evolved into a safe procedure to correct contour deformities in the reconstructed breast. ${ }^{[7]}$

Although some controversy remains with regards to the benefits and risks of autologous fat injections, it is widely used by reconstructive plastic surgeons to correct contour deformities in breast reconstruction. ${ }^{[6]}$ Our experience suggests this is a safe procedure that provides significant improvement to breast contour following reconstruction. This study describes a Karl Schwarz (KS) experience with fat injection to correct contour deformities during breast reconstruction.

\section{METHODS}

\section{Patient population}

The present study was approved by the McGill University Health Centre Ethics Board. A Karl Schwarz (KS), prospectively maintained database of patients who underwent autologous fat injection during breast reconstruction from January 2008 to November 2013 at McGill University Health Center was reviewed. Patient characteristics, breast history, type of breast reconstruction, volume of fat injected, and complications were analyzed retrospectively.

\section{Technique}

Autologous fat was harvested using previously described techniques. ${ }^{[13]}$ Donor sites included medial thighs, flanks, trochanters, arms, or abdominal subcutaneous fat. Under sterile conditions, fat was harvested using the Tulip liposuction system (Tulip Medical Products, San Diego, CA) with a $3 \mathrm{~mm}$ cannula. No donor site morbidity was observed in any of the patients enrolled in this study. The fat was then purified on large Telfa Pads (Covidien, Mansfield, MA) as previously described by Kanchwala et al. ${ }^{[13]}$ Once the fat reached a custard-like consistency, it was loaded into $10-\mathrm{mL}$ syringes [Figure 1]. Based on preoperative topographic markings, fat was then injected into the breasts in $1 \mathrm{~mL}$ aliquots, distributing it evenly in multiple tissue planes, using multiple passes, to visibly correct the previously present contour deformity [Figure 2].

\section{Review of the literature}

As a measure of comparison with previously published studies, we conducted a literature search of the PubMed database using the keywords "fat graft breast" in PubMed. Our search yielded 149 articles, of which 12 met our inclusion criteria requiring that the studies enroll at least
10 patients, measure fat grafting in a clinical context, and include outcomes and complications [Table 1].

\section{RESULTS}

One hundred and twenty-four patients benefited from autologous fat injection from January 2008 to November 2013, for a total of 187 treated breasts. The patients were on average 49.3 years old ( \pm 8.9 years). Fat was most often harvested from the medial thighs (20.5\%), flanks (39.1\%), medial thighs and flanks (2.9\%), trochanters (13.3\%), medial knees (2.7\%), and abdomen (21.9\%). An average of $49.25 \mathrm{~mL}$ (ranging from 8 to $210 \mathrm{~mL}$ ) of fat was injected into each reconstructed breast [Table 2].

A total of 174 breasts in 112 patients were injected with autologous fat during the second stage of breast reconstruction. Thirteen breasts (in 12 separate patients) were injected after having undergone lumpectomy and radiotherapy. Eight breasts (in 5 separate patients) underwent a second round of fat injection 6 months after the initial lipoinjection. Of the 187 treated breasts, 118 were reconstructed with expanders to implants, 45 with deep inferior epigastric perforator (DIEP) flaps, 9 with latissimus dorsi flaps with implants, 4 with transverse rectus abdominis myocutaneous flaps [Table 3]. Thirteen of the breasts had previously undergone lumpectomy and radiotherapy. Representative images of patients treated with autologous fat grafting are shown in Figures 3 and 4.

Six complications in 3 separate patients were noted in the entire series, for a rate of $3.2 \%$. All were in previously radiated breasts. One patient developed an isolated area of fat necrosis but also an occult pneumothorax treated conservatively. One patient developed a cellulitis treated successfully with antibiotics, and another patient developed an infection that was drained with a pig-tail catheter. Oil cysts were noted in 3 breasts.

\section{DISCUSSION}

Our experience suggests that autologous fat injection is a safe and effective procedure for correcting contour deformities following breast reconstruction. Of the 187 treated breasts in our study, we identified complications in only 6 patients for a complication rate of 3.2\%. It should be noted that each of these complications occurred in previously irradiated breasts, which have been associated with impaired healing secondary due to radiation damage. ${ }^{[5]}$ Although our reported rates of fat necrosis and oil cysts are low in nonradiated breasts, it must be noted that they only represent those discovered on physical exam. It is likely that radiographic evaluation would yield higher rates.

Assessment of the literature and the data presented in this article suggest that fat injection can be a safe procedure. Although the studies reviewed demonstrate significant variability among complication rates, our 6 complications in 187 treated breasts lies on the lower end of the spectrum. 

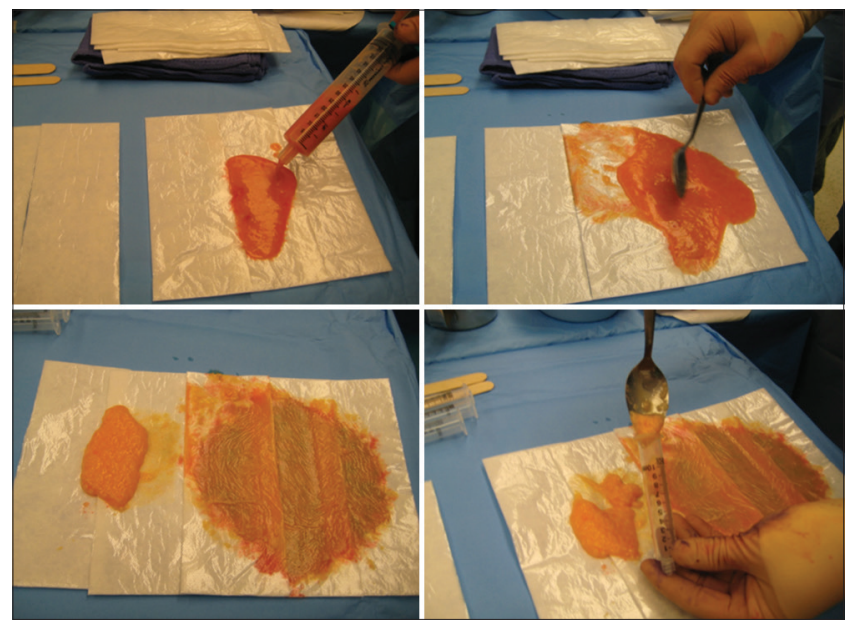

Figure 1: Fat is allowed to separate by gravity and then refined on a Tefla Pad until it reached a custard-like consistency. The refined fat was then transferred in $10-\mathrm{mL}$ syringes

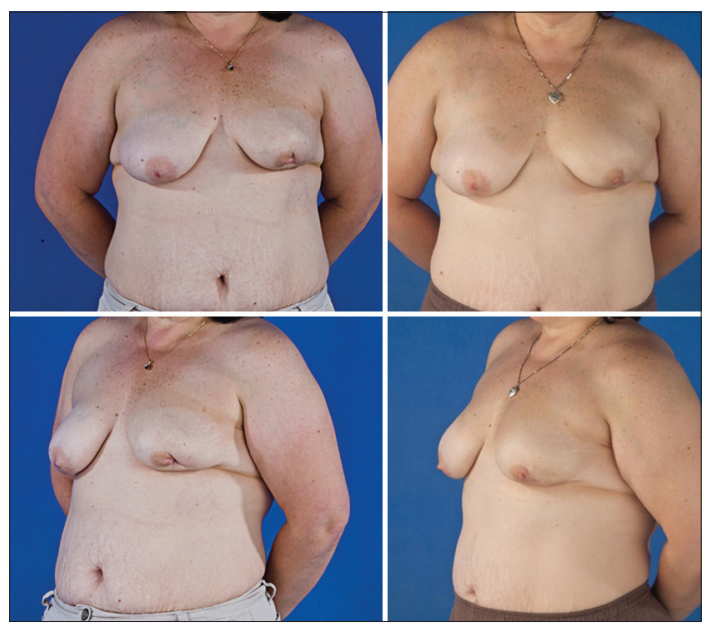

Figure 3: A 52-year-old female who had a left lumpectomy and radiation 3 years ago. She was treated with lipoinjection of the lateral contour deformity

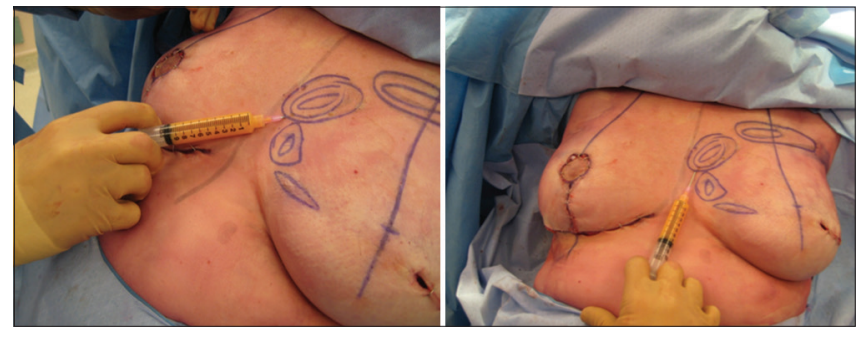

Figure 2: Relying on preoperative topographic markings, fat was injected on the breast in multiple tissue planes, through multiple passes
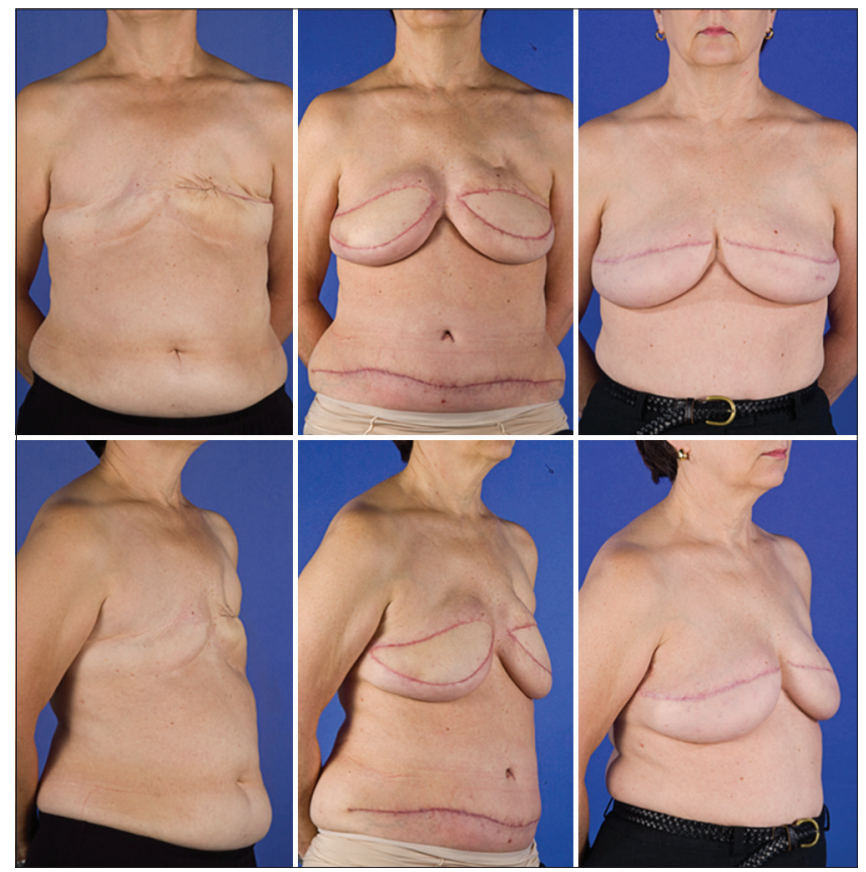

Figure 4: A 62-year-old female with a history of bilateral mastectomy and radiation therapy on the left breast; followed bilateral deep inferior epigastric perforator flap reconstruction. She benefited from 2 rounds of fat injection of the left upper breast contracture and serial excision of breast skin paddle

Table 1: Review of the literature

\begin{tabular}{|c|c|c|c|c|}
\hline Authors & Year & $\begin{array}{l}\text { Number of } \\
\text { patients }(n)\end{array}$ & $\begin{array}{l}\text { Average volume of } \\
\text { fat injection }(\mathrm{mL})\end{array}$ & Complications \\
\hline Pérez-Cano et al..[20] & 2012 & 71 & 140 & $14.1 \%$ of patients developed cysts \\
\hline Khouri et al. ${ }^{[21]}$ & 2012 & 81 & 277 & $16 \%$ of patients report fat necrosis after 1 -year \\
\hline Rubin et al. ${ }^{[22]}$ & 2012 & 27 & 526.5 & $\begin{array}{l}25.5 \% \text { of patients developed oil cysts } \\
17.1 \% \text { of patients developed fat necrosis }\end{array}$ \\
\hline De Blacam et al. ${ }^{[23]}$ & 2011 & 49 & 67 & $\begin{array}{l}3.6 \% \text { of patients developed fat necrosis } \\
1.8 \% \text { of patients developed oil cysts } \\
0.9 \% \text { of patients developed infections }\end{array}$ \\
\hline Kijima et al. ${ }^{[24]}$ & 2012 & 21 & 123 & $\begin{array}{l}4.7 \% \text { of patients developed fat necrosis } \\
4.7 \% \text { of patients developed infection }\end{array}$ \\
\hline Kamakura and Ito ${ }^{[25]}$ & 2011 & 20 & 240 & $11 \%$ of patients developed oil cysts \\
\hline Losken et al. ${ }^{[26]}$ & 2011 & 107 & 40 & $11 \%$ of patients reported fat necrosis, erythema, keloid scarring, and pain \\
\hline Serra-Renom et al. ${ }^{[27]}$ & 2011 & 28 & 39.36 & $0 \%$ fat stable in all patients \\
\hline Sinna et al. ${ }^{[28]}$ & 2010 & 244 & 176 & $\begin{array}{l}2 \% \text { of patients developed fat necrosis } \\
1.2 \% \text { of patients developed infection }\end{array}$ \\
\hline Yoshimura et al. ${ }^{[29]}$ & 2010 & 15 & 264 & $0 \%$ no reported complications \\
\hline $\begin{array}{l}\text { Illouz and } \\
\text { Sterodimas }\end{array}$ & 2009 & 820 & 145 & $\begin{array}{l}9.2 \% \text { of patients developed bruising } \\
4.3 \% \text { of patients developed striae } \\
1.4 \% \text { of patients developed hematomas } \\
0.6 \% \text { of patients developed infections }\end{array}$ \\
\hline Panettiere et al. ${ }^{[31]}$ & 2009 & 61 & 24.5 & $0 \%$ no reported complications \\
\hline
\end{tabular}


Table 2: Source of fat for grafting

\begin{tabular}{lc}
\hline Site & Frequency (\%) \\
\hline Medial thighs & 20.5 \\
Flanks & 39.1 \\
Thighs + flanks & 2.7 \\
Abdomen & 21.9 \\
Trochanters & 13.3 \\
Medial knees & 2.7 \\
\hline
\end{tabular}

Table 3: Initial type of breast reconstruction

\begin{tabular}{lc}
\hline Type of surgery & Frequency (\%) \\
\hline Expander-implant & 62.0 \\
DIEP & 24.1 \\
Latissmus dorsi & 4.8 \\
Lumpectomy defect & 7.0 \\
TRAM & 2.1
\end{tabular}

DIEP: Deep inferior epigastric perforator, TRAM: Transverse rectus abdominis myocutaneous

Despite having experienced few complications, all patients with a suspicious lesion or nodule were encouraged to follow-up with their breast surgeon and

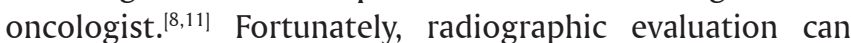
reliably distinguish calcifications, fat necrosis and oil cysts from malignant lesions. ${ }^{[4]}$

The complications identified in our patients occurred only in radiated breasts. Despite the paucity of data regarding fat injection in radiated breasts, there is evidence demonstrating the success of fat injection into radiated tissue. ${ }^{[14]}$ While prior radiation may be a risk factor for fat necrosis, it appears that lipoinjection alleviates the damage associated with radiation. ${ }^{[15,16]}$ Clearly, further studies are needed to elucidate the advantages and pitfalls of fat injection in radiated breasts.

It is important to point out that familiarity with the technical aspects of fat injection affects the incidence of complications. ${ }^{[7,8]}$ While the incidence of fat necrosis and graft resorption is reduced when small aliquots are injected in multiple tissue planes, there is evidence that the long-term viability is increased with greater overall injection volumes. ${ }^{[10,12,17]}$

A discussion on the safety of fat injection would not be complete without addressing the potential effects of lipoinjection on local breast cancer recurrence. The increase in vascularity promoted by injected adipose tissue may present a theoretical risk for recurrence. ${ }^{[17]}$ A study by Petit et al..$^{[18,19]}$ describes early follow-up data suggesting that fat grafting does not present an increased risk for cancer recurrence, however, a follow-up cohort study by the same author suggests that the risk for recurrence could increase in women with high-grade intraepithelial neoplasia under the age of 50. An additional study funded by The Plastic Surgery Foundation is ongoing to further evaluate the oncologic safety of fat grafting in breast cancer patients.

In conclusion, contour irregularities are common problems associated with breast reconstruction and can lead to suboptimal cosmetic results. Fat injection is a powerful tool that provides surgeons the ability to achieve esthetically superior results. Meticulous technique and proper planning, particularly assessing the recipient site and limiting injection volumes, allows surgeons to deliver results with low complication rates.

\section{REFERENCES}

I. Chajchir A, Benzaquen I. Liposuction fat grafts in face wrinkles and hemifacial atrophy. Aesthetic Plast Surg 1986; 10:1 I5-7.

2. Chajchir A, Benzaquen I. Fat-grafting injection for soft-tissue augmentation. Plast Reconstr Surg 1989;84:921-34.

3. Ellenbogen R. Free autogenous pearl fat grafts in the face: a preliminary report of a rediscovered technique. Ann Plast Surg 1986;16:179-94.

4. Report on autologous fat transplantation. ASPRS Ad-hoc Committee on New Procedures, September 30, 1987. Plast Surg Nurs 1987;7:140-I.

5. Coleman SR, Saboeiro AP. Fat grafting to the breast revisited: safety and efficacy. Plast Reconstr Surg 2007; I 19:775-85.

6. Kling RE, Mehrara BJ, Pusic AL, Young VL, Hume KM, Crotty CA, Rubin JP. Trends in autologous fat grafting to the breast: a national survey of the American society of plastic surgeons. Plast Reconstr Surg 2013;132:35-46.

7. Delay E, Garson S, Tousson G, Sinna R. Fat injection to the breast: technique, results, and indications based on 880 procedures over 10 years. Aesthet Surg J 2009;29:360-76.

8. Gutowski KA, ASPS Fat Graft Task Force. Current applications and safety of autologous fat grafts: a report of the ASPS fat graft task force. Plast Reconstr Surg 2009; 124:272-80.

9. Cotrufo S, Mandal A, Mithoff EM. Fat grafting to the breast revisited: safety and efficacy. Plast Reconstr Surg 2008;121:701.

10. Mu DL, Luan J, Mu L, Xin MQ. Breast augmentation by autologous fat injection grafting: management and clinical analysis of complications. Ann Plast Surg 2009;63: I 24-7.

II. Walden JL. Complications after autologous fat injection to the breast. Plast Reconstr Surg 2009;124:326-7.

12. Choi M, Small K, Levovitz C, Lee C, Fadl A, Karp NS. The volumetric analysis of fat graft survival in breast reconstruction. Plast Reconstr Surg 2013;|31:|85-9|.

13. Kanchwala SK, Glatt BS, Conant EF, Bucky LP. Autologous fat grafting to the reconstructed breast: the management of acquired contour deformities. Plast Reconstr Surg 2009;124:409-18.

14. Phulpin B, Gangloff P, Tran N, Bravetti P, Merlin JL, Dolivet G. Rehabilitation of irradiated head and neck tissues by autologous fat transplantation. Plast Reconstr Surg 2009; 123:1 I87-97.

15. Sultan SM, Stern CS, Allen RJ Jr, Thanik VD, Chang CC, Nguyen PD, Canizares O, Szpalski C, Saadeh PB, Warren SM, Coleman SR, Hazen A. Human fat grafting alleviates radiation skin damage in a murine model. Plast Reconstr Surg 201 I; I28:363-72.

16. Salgarello M, Visconti G, Farallo E. Autologous fat graft in radiated tissue prior to alloplastic reconstruction of the breast: report of two cases. Aesthetic Plast Surg 2010;34:5-10.

17. Khonji N. Breast reconstruction using autologous fat. Br J Surg 20 I 0;97:795-6.

18. Petit JY, Botteri E, Lohsiriwat V, Rietjens M, De Lorenzi F, Garusi C, Rossetto F, Martella S, Manconi A, Bertolini F, Curigliano G, Veronesi P, Santillo B, Rotmensz N. Locoregional recurrence risk after lipofilling in breast cancer patients. Ann Oncol 20I2;23:582-8.

19. Petit JY, Rietjens M, Botteri E, Rotmensz N, Bertolini F, Curigliano G, Rey P, Garusi C, De Lorenzi F, Martella S, Manconi A, Barbieri B, Veronesi P, Intra M, Brambullo T, Gottardi A, Sommario M, Lomeo G, lera M, Giovinazzo V, Lohsiriwat $V$. Evaluation of fat grafting safety in patients with intraepithelial neoplasia: a matched-cohort study. Ann Oncol 2013;24:1479-84.

20. Pérez-Cano R, Vranckx JJ, Lasso JM, Calabrese C, Merck B, Milstein AM, Sassoon E, Delay E, Weiler-Mithoff EM. Prospective trial of adipose-derived regenerative cell (ADRC)-enriched fat grafting for partial mastectomy defects: the RESTORE-2 trial. Eur J Surg Oncol 20I2;38:382-9.

21. Khouri RK, Eisenmann-Klein M, Cardoso E, Cooley BC, Kacher D, Gombos E, Baker TJ. Brava and autologous fat transfer is a safe and effective breast augmentation alternative: results of a 6-year, $8 \mathrm{I}$-patient, prospective multicenter study. Plast Reconstr Surg 2012;129:1 I73-87.

22. Rubin JP, Coon D, Zuley M, Toy J, Asano Y, Kurita M, Aoi N, Harii K, Yoshimura K. Mammographic changes after fat transfer to the breast 
compared with changes after breast reduction: a blinded study. Plast Reconstr Surg 2012;129:1029-38

23. De Blacam C, Momoh AO, Colakoglu S, Tobias AM, Lee BT. Evaluation of clinical outcomes and aesthetic results after autologous fat grafting for contour deformities of the reconstructed breast. Plast Reconstr Surg 2009; I 24:272-80.

24. Kijima Y, Yoshinaka H, Hirata M, Umekita Y, Sohda M, Koriyama C, Mizoguchi T, Arima H, Nakajo A, Ishigami S, Ueno S, Natsugoe S. Clinical and pathologic evaluation of implanted free dermal fat grafts after breast cancer surgery: a retrospective analysis. Surgery 2012;151:444-55.

25. Kamakura T, Ito K. Autologous cell-enriched fat grafting for breast augmentation. Aesthetic Plast Surg 201 I;35: 1022-30.

26. Losken A, Pinell XA, Sikoro K, Yezhelyev MV, Anderson E, Carlson GW. Autologous fat grafting in secondary breast reconstruction. Ann Plast Surg 20II;66:5I8-22.

27. Serra-Renom JM, Muñoz-Olmo J, Serra-Mestre JM. Treatment of grade 3 tuberous breasts with Puckett's technique (modified) and fat grafting to correct the constricting ring. Aesthetic Plast Surg 20I I;35:773-8I.

28. Sinna R, Delay E, Garson S, Delaporte T, Toussoun G. Breast fat grafting (lipomodelling) after extended latissimus dorsi flap breast reconstruction: a preliminary report of 200 consecutive cases. J Plast Reconstr Aesthet Surg 2010;63:1769-77.

29. Yoshimura K, Asano Y, Aoi N, Kurita M, Oshima Y, Sato K, Inoue K, Suga H, Eto $\mathrm{H}$, Kato $\mathrm{H}$, Harii K. Progenitor-enriched adipose tissue transplantation as rescue for breast implant complications. Breast J 2010;16:169-75.

30. Illouz YG, Sterodimas A. Autologous fat transplantation to the breast: a personal technique with 25 years of experience. Aesthetic Plast Surg 2009;33:706-I5.

31. Panettiere P, Marchetti L, Accorsi D. The serial free fat transfer in irradiated prosthetic breast reconstructions. Aesthetic Plast Surg 2009;33:695-700.

How to cite this article: Tahiri Y, Kanevsky J, Vorstenbosch J, Lee J, Schwarz K. Fat injection to correct contour deformities of the reconstructed breast: a single surgeon experience. Plast Aesthet Res 2015;2:115-9.

Source of Support: Nil, Conflict of Interest: None declared.

Received: 03-09-2014; Accepted: 27-02-2015 